\title{
NOTES FOR AUTHORS
}

\author{
Please see the complete version ("Instructions for Contributors") at journals.cambridge.org/ber
}

Styles of Paper

Bulletin of Entomological Research publishes two types of paper:

- Full research papers

- Reviews

If the referees and editors judge a paper to be particularly significant then it will be fast-tracked for publication.

We also welcome 'Letters to the Editor' with comments on recently published papers.

\section{Manuscript Preparation}

\section{Language}

Manuscripts should be in English.

Manuscript content

Manuscripts should be prepared in Microsoft Word or similar according to the following structure:

- The text, divided under appropriate headings. Clearly differentiate between primary (bold, large font size), secondary (bold, text font size) and tertiary (italics) headings

- Acknowledgements (if any)

- References (for further information about presenting references please see below)

- Tables, either at the end of the manuscript or as separate files. Tables should be numbered consecutively with Arabic numerals and every table should be mentioned at least once in the text.

- Illustrations should be submitted as separate files in TIF or EPS format but captions should be listed at the end of the manuscript text.

Abstract

Each paper must commence with an accurate, informative abstract. It should not exceed 250 words. A short title should also be provided for use as a running head.

\section{References}

References must be based on the name and year system, give full journal titles and conform to the following styles:

Journal paper:

Thiery, D., Monceau, K. \& Moreau, J. (2014) Larval intraspecific competition for food in the European grapevine moth Lobesia botrana. Bulletin of Entomological Research 104, 517-524.

Whole book:

Krantz, G.W. \& Walter, D.E. (2009) A Manual of Acarology. Texas, Texas Tech University Press.

Chapter in book:

Jervis, M.A. \& Heimpel, G.E. (2005) Phytophagy. pp 525-550 in Jervis, M.A. (Ed.) Insect Natural Enemies: A Practical Perspective. Dordrecht, The Netherlands, Springer.

Proceedings:

Virgilio, M., Backeljau, T. \& DeMeyer, M. (2007) Incongruence of phylogenetic signals and shared polymorphisms prevent the molecular characterization of the Ceratitis fasciventris, $C$. anonae, C. rosa complex (Diptera: Tephritidae). p. 520 in Proceedings of the 11th Congress of the European Society for Evolutionary Biology, Upsalla, Sweden.

Please list papers by more than two authors, but with the same first author, by year sequence and alphabetically within each year. Citation of authors in the text should appear in the form: Thiery (2014) or (Thiery, 2014). Authors should be cited in chronological order as: (Jervis et al., 2005; Krantz \& Walter, 2009).

Tables

Tables should be in a simple form and should not be used if text or illustrations give the same information. They can either be submitted as separate files (Microsoft Word or Excel) or embedded within the main manuscript file. Each table must have a clear and concise caption.

Illustrations

Illustrations should be submitted in TIF or EPS format at approximate final publication size. Resolution of artwork should be at the following minimum resolutions: Line artwork (black \& white), 1200dpi; Combination, i.e. line/tone (greyscale), 800dpi; Black \& White halftone (greyscale), 300dpi; and Colour halftone, 300dpi. Comprehensive guidance on creating suitable electronic figures is available at http://dx.sheridan.com/guidelines/digital_ art.html where you will find extensive guidelines on preparing electronic figures. An online preflighting tool (http://dx.sheridan. com/index.html) is also available where you can check if your figures are suitable for reproduction. Captions should be listed at the end of the manuscript text.

\section{Supplementary Material}

Additional information which due to its nature does not lend itself to print media (examples- full data sets, movie or sounds files etc...) may be submitted for online-only publication. Please see full details ("Instructions for Contributors") at journals.cambridge. org/ber.

\section{Technical and Nomenclature Standards}

All work should use SI units as standard. Anatomical terms can be a mixture of the English vernacular and Latin, depending on current usage.

\section{Manuscript Preparation}

We kindly ask that you follow the instructions below when preparing your manuscript for submission. This will minimize the risk of errors being introduced during the publishing process.

- Use double-line spacing and ample margins (at least $2.5 \mathrm{~cm}$ ) on each side.

- Do not underline anything

- Number each line consecutively across the pages of the manuscript, rather than within pages

- Number every page (preferably the top right corner)

- Do not indent the start of each paragraph

- Use italics for taxonomic nomenclature and bold for headings

- Use standard abbreviations (e.g. Fig. and Figs) and SI units

- Use British rather than American Spellings and ' $z$ ' rather than 's' spellings in words with 'ize'.

\section{Voucher specimens}

The deposition of voucher specimens should be considered where appropriate.

\section{Manuscript Submission}

All manuscripts should be submitted via our on-line system, Editorial Manager, at http://www.editorialmanager.com/ber. New users will need to register first.

\section{Peer review}

Communications for peer review will be by email as far as possible. Authors are invited to suggest the names and contact details of at least two potential referees and are asked to provide keywords indicating the content of the manuscript. Please also give a brief description (no more than 50 words) of why the manuscript is an important contribution to entomology research.

\section{Publication}

\section{Copyright}

Authors will be supplied with an agreement to publish form, which must be completed and returned to the Publisher. Papers are accepted on the understanding that the work has been submitted exclusively to the Bulletin and has not been previously published elsewhere.

Proofs

Authors will receive a PDF file of page proofs by email, and will be asked to return corrected proofs within 72 hours.

\section{Offprints}

The author (or main author) of an accepted paper will receive a free PDF of their paper. Paper offprints are available for a fee and should be ordered at proof stage. 


\section{saminas \\ Entomological Research}

Review Papers

J.M. Medlock, K.M. Hansford, V. Versteirt, B. Cull, H. Kampen, D. Fontenille, G. Hendrickx, H. Zeller, W. Van Bortel and F. Schaffner

An entomological review of invasive mosquitoes in Europe

B. Alten, Y. Ozbel, K. Ergunay, 0.E. Kasap, B. Cull, M. Antoniou, E. Velo, J. Prudhomme,

R. Molina, A.-L. Bañuls, F. Schaffner, G. Hendrickx, W. Van Bortel and J.M. Medlock

Sampling strategies for phlebotomine sand flies (Diptera: Psychodidae) in Europe

\section{Research Papers}

C. Mangudo, J.P. Aparicio and R.M. Gleiser

Tree holes as larval habitats for Aedes aegypti in urban, suburban and forest habitats in a dengue affected area

L. Goane, A. Casmuz, H. Salas, E. Willink, A. Mangeaud and G. Valladares

Impact of natural control agents of the citrus leafminer Phyllocnistis citrella on lemon trees varies among seasons

A. Gilabert, C.-A. Dedryver, S. Stoeckel, M. Plantegenest and J.-C. Simon

Longitudinal clines in the frequency distribution of 'super-clones' in an aphid crop pest

A. Zurita, R. Callejón, M. De Rojas, M.S. Gómez López and C. Cutillas

Molecular study of Stenoponia tripectinata tripectinata (Siphonaptera: Ctenophthalmidae: Stenoponiinae)

from the Canary Islands: taxonomy and phylogeny

E. AlSuhaibani, C.C. Voudouris, R. Al-Atiyat, A. Kotzamumin, J. Vontas and J.T. Margaritopoulos Identification of a point mutation in the ace1 gene of Therioaphis trifolli maculata and detection of insecticide resistance by a diagnostic PCR-RFLP assay

G.-J. Brandon-Mong, H.-M. Gan, K.-W. Sing, P.-S. Lee, P.-E. Lim and J.-J. Wilson

DNA metabarcoding of insects and allies: an evaluation of primers and pipelines

C. Wallinger, D. Sint, F. Baier, C. Schmid, R. Mayer and M. Traugott

Detection of seed DNA in regurgitates of granivorous carabid beetles

X. Shang, Y. Yao, W. Huai and W. Zhao

Population genetic differentiation of the black locust gall midge Obolodiplosis robiniae (Haldeman)

(Diptera: Cecidomyiidae): a North American pest invading Asia

A. Birke, E. Acosta and M. Aluja

Limits to the host range of the highly polyphagous tephritid fruit fly Anastrepha ludens in its natural habitat

E.B. Argüello Caro, A.D. Dumón, M.F. Mattio, V. Alemandri and G. Truol

A molecular framework for the identification of planthopper vectors (Hemiptera: Delphacidae) of central Argentina

J. A. Martínez-Ibarra, B. Nogueda-Torres, M. Á. Cárdenas-De la Cruz, M. E. Villagrán, J. A. de Diego-Cabrera and R. Bustos-Saldaña

Biological parameters of interbreeding subspecies of Meccus phyllosomus (Hemiptera: Reduviidae:

Triatominae) in western Mexico

D. Liu, Y. Yuan, M. Li and X. Qiu

Effects of dietary quercetin on performance and cytochrome P450 expression of the cotton bollworm,

Helicoverpa armigera

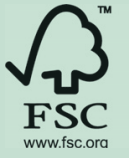

